\title{
Network Approach to Regime Type and Global Internet Connectedness*
}

\author{
Hyunjin Seo $^{\dagger 1}$ and Stuart Thorson ${ }^{\ddagger 2}$ \\ ${ }^{1}$ William Allen White School of Journalism and Mass Communications, \\ University of Kansas \\ ${ }^{2}$ Maxwell School, Syracuse University
}

September 19, 2017

\begin{abstract}
We explore the relationship between regime type and country access to the Internet at both domestic and global levels by conducting longitudinal analyses of economic, population, and Internet data between 2002 and 2011. In particular, we investigate how a country's position in the global Internet network is associated with the country's type of political institution while attempting to take into account its economic growth and population (so-called scale effects). Our analysis shows that liberal democracies dominated the global Internet network both in 2002 and in 2011, followed by polyarchies and electoral democracies. Finally, our panel regression and network analyses suggest that it is important to consider network characteristics in investigating whether and how a country's regime type influences the country's Internet adoption. We discuss implications of these and other findings for idea flows and economic developments.
\end{abstract}

${ }^{*}$ This is an accepted version of the manuscript published by Taylor \& Francis in Journal of Global Information Technology Management in 2017, available online: http://dx.doi.org/10.1080/1097198X.2017.1354597.

Citation: Seo, H., \& Thorson, S. "Network Approach to Regime Type and Global Internet Connectedness" (2017). Journal of Global Information Technology Management, 20(3), 141-155. http://dx.doi.org/10.1080/1097198X.2017.1354597

†hseo@ku.edu

†thorson@syr.edu 


\section{Introduction}

Looking at data from the late $20^{\text {th }}$ century generally, though not unequivocally, supports the notion that richer countries tend to be democratic (Lipset, 1959; Magee \& Doces, 2015). The specifics of this relationship are complicated, though there is general agreement that increasing political freedoms can help generate economic growth at least at low levels of economic development. Barro'sBarro, 1996 longitudinal analysis of approximately 100 countries between 1960 and 1990 found that when variables including rule of law, free markets, low government consumption, initial level of per-capita GDP, and high human capital were held constant, the relationship between democracy and economic growth was mildly negative. One explanation is that democratization helps economic growth where there are low levels of freedom but then begins to retard growth as levels of political freedom become at least moderate.

In this paper we use the concept of regime type to compare the governance structures of countries. Specifically, we use regime type as a proxy for the degree to which a given country exhibits the characteristic of being democratic. While the notion of democracy is in many ways a contested concept, political scientists have developed empirical measures Pemstein, Meserve, and Melton, 2010. For our purposes, and we will say more about this in the Data section below, we want to distinguish between various kinds of democracies ranging from those which involve minimally competitive elections (for example, Albania) to those which assert full equality under the law (for example, Australia). These different flavors of democracy taken together are further distinguished from closed autocracies (minimal or no elections; for example, Saudi Arabia) and multiparty autocracies (multiple parties but little effective competition; for example, Tajikistan).

Technology has often been cited as a key component of economic development and it has been argued that democratic institutions enhance the development of advanced technology. For example, Aghion, Alesina, and Trebbi, 2007 argue, with some empirical support, that political rights often associated with democratic regimes permit easy entry for new businesses and that this can be especially important in catalyzing innovation at or near the technological frontier in contrast with an autocratic regime in which a new entry would require central government authorization.

For our purposes, a particularly important look at the role of technology is provided by Paul Romer who develops an argument for the endogenous role played by technology in economic development. In Romer, 1990 he argues that economic development results in part from developing new ways of combining physical raw materials. For example, new value is created when ways are found to use rare earth metals in building cell phones and television sets. These new ideas are interesting economic objects in that they often have properties which distinguish them from more conventional objects. We elaborate on this in the Background section.

At a fundamental level, ideas are information. And, high speed, standards-based digital networks are an essential medium for information flow in this networked information age Standage, 2013. The primary current example is the global Internet. Coupled with modern search engines, once an idea becomes available in one place it nearly instantly becomes mirrored and locatable from anywhere with appropriate Internet access. This networking of virtualized information has the potential to speed up the rate of technology development. 
For this to actually happen, there are infrastructure investments which must be made and maintained. Additionally, citizens must have sufficient access to devices which can connect to the Internet, capture information, and as pointed out in Benkler, 2006, there must be enough slack that people are able to explore novel ways of creating new value by mutating that information. From a political perspective, this entails relatively unrestricted access to the Internet along with a legal system offering robust guarantees that creators of new information will be able to capture some of the value of that information.

Countries differ in how they are integrated with the Internet. These differences are at both the domestic (how much access do a country's citizens have) and global (how connected is the country to the global Internet) levels. The primary purpose of this paper is to examine the impact of regime type on a country's access to the Internet at both country and global levels while controlling for some country characteristics known to influence the country's Internet adoption. In particular, we aim to provide insight into whether and how a country's regime type is associated with the country's connections with other countries via the Internet (global level). While previous studies examined the influence of regime type on technology adoption or vice versaGuillén and Suárez, 2005; Seo and Thorson, 2012; Kedzie, 1997; Milner, 2006; Norris, 2001; Rød and Weidmann, 2015, little research has examined the topic at both country and global levels. We aim to fill this gap in the literature by analyzing relevant data from 2002 to 2011 using network analysis and panel regression. To provide a more complete view of the relationship between regime type and Internet connectedness, it is important to look beyond country specific variables and consider how well connected and central that country is within the network.

\section{Background}

\subsection{Regime Type and Internet Adoption}

Whether or how forms of political institutions, regime type, influence the government's Internet adoption or whether the government's Internet adoption affects its democratic process has been a topic of great interest in recent years Guillén and Suárez, 2005; Seo and Thorson, 2012; Kedzie, 1997; Milner, 2006; Norris, 2001; Rød and Weidmann, 2015. Empirical and theoretical studies in this area have presented somewhat conflicting arguments. These mainly divide into two groups of thought. The first argues that there is a significant association between the type of political institution and the country's adoption of digital communication technologies such as the Internet with democratic countries being more likely to adopt the InternetGuillén and Suárez, 2005; Kedzie, 1997; Milner, 2006. In contrast, the second group argues that the Internet adoption does not always help a country become more open or democratic Rød and Weidmann, 2015.

Examining data from roughly 200 countries from 1991 to 2001, Milner, 2006 found that political institutions significantly influenced the spread of the Internet even after controlling for alternative explanations such as economic development. In particular, Milner argued that regime type plays an important role in this with democracies adopting the Internet at a much faster pace than autocracies. Milner's findings are consistent with Guillen and Suarez's study Guillén and Suárez, 2005 that showed the democracy score of the country was a significant 
predictor of the country's number of Internet users and hosts. Following the so-called Arab Spring political and social uprisings in some Middle Eastern and North African countries, several studies emphasized the role of the Internet and digital communication technologies in facilitating grass roots political movements Howard and Hussain, 2011; Seo and Thorson, 2012 .

The Islamic Republic of Iran and Democratic People's Republic of Korea (North Korea) continue to rank at the bottom in terms of both democracy and Internet adoption Freedom House, 2015a, 2015b. While systematic research on the countries' Internet access and adoption has been limited largely due to restrictions to access to these countries, there has been empirical evidence-based reports that provide a glimpse of Internet policies in the countries. Iran's domestic Internet policies are designed to legitimize the government's efforts to monitor and control its citizens' Internet access and filter content online on a massive scale Global Internet Policy, 2015. While Iranian President Rouhani, in the wake of his election in 2013, promised to a shift in the domestic Internet policies, no significant policy change has yet materialized. In the case of North Korea, one of the world's least globally connected countries, ordinary citizens are allowed access only to a national intranet. Global Internet access is granted only to a small group of high-level officials and scientists.

However, others have argued that the association between the Internet and democratic development is overstated Rød and Weidmann, 2015. For example, based on an empirical analysis of Internet use in authoritarian regimes from 1993 to 2010, Rød and Weidmann, 2015 claimed that autocracies concerned about the domestic information environment are more likely to introduce the Internet than other autocracies. In addition, their data showed that movements toward democracy were more frequent in autocratic countries with low Internet penetration. These findings led them to conclude that the Internet had no effect on political institutions and the assumption that "the Internet fosters democratization" is overstated (p. 348).

\subsection{Technology, Scale, and Ideas}

Traditional activities, both public and private, designed to help produce ideas and modes of implementing those ideas have taken the form of developing human capital through higher education, national labs, public libraries, and private sector research and development labs. Countries have varied considerably in the mix of public and private sector responsibility for these. Importantly, at least through most of the $20^{\text {th }}$ century, these idea development activities have largely been carried out within national borders. That is, national policies controlled the specific mix of public and private activities aimed at idea development Wagner, 2008; Leydesdorff, Wagner, Park, and Adams, 2013. More recently, the global Internet providing a geographically dispersed virtual bazaar of information capable of being mutated into new and valuable ideas plays an increasingly prominent role.

Paul Romer developed an argument for the endogenous role played by technology in economic development Romer, 1990. He argued that ideas are information which, when implemented, possibly can be used to solve a problem. For example, an idea for manufacturing particular kind of product. However, to actually make the product that idea must be instantiated in someone's head or a program controlling a robot and applied to any necessary material ingredients to produce a instance of the product. 
The material ingredients have fairly conventional economic properties. That is, they are excludable as the owner of these goods can exclude others from using the good absent, say, a payment. And they are rivalrous (my using that particular instance of that ingredient means others cannot). Note here that excludability may depend upon a rule of law supporting robust expectations regarding the enforceability of contracts.

Moreover, the product itself is both rivalrous and excludable. An instance of a product can only be in one place at a time and if I possess that instance I can rightfully deny access to others. Further, the person (or robot) responsible for implementing the idea is rivalrous as the person (machine) cannot be simultaneously somewhere and somewhere else. However, the value of the product is not simply a linear combination of the value of the robot together with the value of the raw ingredients. The idea, which led to the product, is a crucial component of the product's ultimate value. That idea has a virtual existence apart from its physical implementation. In other words, it is not necessarily rivalrous nor need it be completely excludable. To some extent this may depend upon details of national intellectual property laws which will generally vary from country to country.

Ideas, implemented in computer code, English language, or whatever representation language, may be nonrivalrous precisely because that idea is capable of being simultaneously implemented in any number of physical entities. Moreover, the idea can be mutated to produce "improved" products with features perhaps unimagined at the time the original idea was developed. The nonrivalrous nature of ideas suggests that it may not always be possible to fully exclude access to ideas. Examples of this range from ideas for developing the atomic bomb to Steve Jobs watching a presentation of a windowing system at Xerox PARC and going on to develop the Apple Macintosh. This ongoing process of idea sharing, mutating, development, and commercialization helps to drive technological development.

One of Romer's insights was, following Schumpeter, 2013, to note that once we acknowledge that nonrivalrous inputs can add economic value while not being fully excludable and assume that rational economic agents will thus have reason (incentive) for developing new ideas, there is a rationale for making technology development endogenous to economic growth models. The price paid for this is that the resultant increasing returns to scale means production functions can no longer be assumed to be convex and decentralized equilibria cannot be guaranteed to exist. This led Romer to propose a monopolist competition theory of economic development in which ideas are both nonrivalrous and not necessarily fully excludable.

In the neoclassical theory of economic growth, ideas were treated as exogenous. Ideas just sort of happened outside the formal growth models. Romer's incorporating ideas within his growth model is important since it provides agents incentives for seeking out and mutating ideas (the incentive comes from their being able to capture privately some of the value associated with the idea). Moreover, and importantly for our argument, it is reasonable to think that the number of new ideas produced will be some increasing function of the number of people trying to develop ideas. An immediate implication of this is what are generally termed scale effects Jones, 1999. All else being equal, the larger the population of potential idea producers, the greater the economic growth potential. The issue then becomes how to identify that population - is it simply the count of people or, as we argue, is it better thought of as being an index of the number of people having credible access to the existing pool of ideas.

Summarizing to this point, there is considerable empirical evidence to suggest that ideas 
drive technology development and, along with traditional capital, matter to economic growth. Assuming Romer models of growth, there are endogenous incentives for developing and commercializing ideas. A consequence of this is that national government policies can affect incentives in such a way as to support the production of more ideas. Moreover, continuing to assume scale effects, we would expect large countries, and especially large countries whose citizens have good access to the global bazaar of ideas known as the Internet, to do better than smaller countries. At the same time, we might expect government policies which have the consequence of restricting citizen access to the Internet to effectively reduce the scale of that country. The two Koreas provide useful illustration of this. South Korea, a relatively small country in area and population, has since late last century pursued a government directed policy of expanding Internet connectivity and providing opportunities for its citizens to study abroad. The South Korean economy, the so-called miracle on the Han, punches well above its weight. On the other hand, North Korea, also a relatively small country, has pursued a policy of isolation and has permitted citizens extremely limited opportunity for Internet access and study abroad. Its economy is one of the poorest in the world.

\section{Data}

The empirical analyses in this paper are based on a panel dataset of countries over the ten-year period from 2002 to 2011. Depending upon the variables being analyzed, the panel includes between 171 and 200 countries. The particular time period was chosen both because of data availability and our objective of looking at the impact of regime type on Internet connectedness. It was only around 2002 that most all countries report robust connection with the global Internet.

The panel was constructed by combining data from several sources. Values for country population $(P O P)$, gross national income ${ }^{1}(G N I)$, and Internet Users per 100 people (InetUsers) measures were taken from the World Bank World Development Indicators. The regime type (RegimeType) variable is that reported on in Møller and Skaaning, 2013 and available at http://ps.au.dk/forskning/forskningsprojekter/dedere/datasets/. Country global bandwidth (Bandwidth) measures were calculated from data curated by TeleGeography TeleGeography, 2012.

GNI figures are reported in current dollars. World Bank estimates of InetUsers are based upon data from the International Telecommunication Union and World Telecommunication/ICT Development Report. A description of the method used to calculate Bandwidth is in Seo and Thorson, 2015.

Our use of regime type refers to a general characterization of the governance system in a country. Given the time period of our study, our focus is on the degree to which a country is democratic. There have been a variety of attempts to measure democracy Munck and Verkuilen, 2002. While there is evidence that these different measures tend to correlate with one another, differences between them can matter Pemstein et al., 2010.

The Regime Type variable we use is fully described in Møller and Skaaning, 2013 and,

\footnotetext{
${ }^{1}$ GNI reflects the total domestic and foreign income earned by residents of a country and thus includes a country's Gross Domestic Product plus income earned from other countries. Data are reported in current dollars.
} 
for democracies, based upon the Freedom House annual survey of electoral democracies Møller and Skaaning, 2010. The values of RegimeType are: closed autocracy (minimal or no elections), multiparty autocracy (existence of multiple parties even if not competitive), minimalist democracy (political competition with uncertain outcomes), electoral democracy (requires more rigorous electoral procedures), polyarchy (requires freedom of speech and association), and liberal democracy (requires equality under the law). Example counties with classification in 2011 are Iran (closed autocracy), Egypt (multiparty autocracy), Guatemala (minimalist democracy), Indonesia (electoral democracy), Republic of Korea (polyarchy), and France (liberal democracy).

We use the full six value Regime Type scale for much of our subsequent analysis. Figure 1 shows the distribution of Regime Type values by year for the 191 countries for which we had measures in all ten years ${ }^{2}$ However, there are several times that we will dichotomize the variable into democracies and autocracies by collapsing the two autocracy categories and the four democracy categories. For the dichotomized variable the number of democratic countries in the panel fell slightly from 120 in 2002 to 115 in 2011. Over the same period the number of countries categorized as autocracies increased from 71 to 76 . Figure 2 shows the distribution over the period. As can be seen in Figure 1, the number of liberal democracies increased over the period and the number of closed autocracies decreased.

[Figure 1 about here.]

[Figure 2 about here.]

\section{Analysis and Results}

\subsection{Panel Regression}

As discussed above, previous research Milner, 2006 has examined the effect of regime type on Internet adoption by seeing whether democracies tend to show higher rates of adoption than do autocracies. Past studies generally measure Internet adoption using variables such as the number of Internet users (normalized by population) in a country or the number of Internet hosts (devices directly connected to the Internet) in a country Milner, 2006; Rød and Weidmann, 2015; Guillén and Suárez, 2005. Independent variables considered have included some combination of regime type, level of economic well-being, and population measures. The general result is that democracies show a higher level of Internet adoption than do autocracies. There also tends to be a scale effect using population as a proxy.

Inherent in this approach is the assumption that country level outcomes (Internet adoption) are functions of country level institutions, level of development, and scale measured by log of population. While empirical results tend to support this claim, they do not fully account for country differences. To illustrate this we performed a simple fixed effects panel regression Croissant and Millo, 2008 on our country data with InetUsers as the dependent variable and per capita $\log (G N I)$, Regime Type, and $\log (P O P)$ as independent variables. Consistent with expectations based on prior literature, the estimated $\beta$ for all three independent variables were positive and statistically significant (in all cases $p<0.01$ ).

\footnotetext{
${ }^{2}$ The color coding in Figure 1 will be used in subsequent visualizations to distinguish RegimeType values.
} 
We also consider another Internet adoption dependent variable-logged international bandwidth per capita. Globally, international Internet bandwidth has increased from less than 1 Tbps in 2002 to about 55 Tbps in 2011. International Internet bandwidth refers to the amount of data that can be transferred over the Internet, across national borders, in a given amount of time. A country's international Internet bandwidth connection to another country is an upper bound on direct country to country Internet traffic flow and has been argued to be a good indicator of transnational Internet traffic flows Barnett and Park, 2005. We will use a country's international Internet bandwidth as a proxy for that country's level of connection to the global Internet as distinct from Internet users per 100 which provides a measure of citizen connection to the Internet. This distinction could be important if, say, a country has good international connectivity but relatively few of its citizens are able to make use of that capacity. We computed a given country's gross international bandwidth by summing one half the bandwidth associated with each country with which it shares a direct Internet connection (the one half stems from the convention of assigning each directly connected country one half of the bandwidth in their shared connection).

We calculated each of our panel country's total international bandwidth for each of the years between 2002 and 2011. As a first approximation, countries with more international bandwidth might be thought of as being heavier Internet adopters. To assess whether this variable relates to our independent variables in the same way as did Internet users per 100, we did another fixed effects panel regression now with logged international bandwidth per capita as the dependent variable and the same independent variables as before (per capita $\log (G N I)$, Regime Type, and $\log (P O P)$. Results from these two models are shown in Table $1^{3}$. Interestingly, the Regime Type $\beta$ is now essentially zero and no longer statistically significant. Also, the population (scale) variable now has a negative sign.

[Table 1 about here.]

Does this mean regime type does not matter for Internet adoption at the international level? One way of looking at this is to consider that the regression model is attempting to account for country variables using a linear combination of other country variables. Such an approach ignores the interconnectedness of the global Internet. A country's position within the global Internet is a function not only of what it does but also how it interconnects with other countries and how those countries interconnect with it. The nature of these interconnections may be especially important when dealing with variables such as international bandwidth, population, and GNI. These generally show a heavy right tail with means much higher than medians. Thus the standard practice of logging them. However this still does not take into account of country position in the Internet from a network perspective. Fortunately, our international bandwidth data does permit such an analysis and we turn now to that.

\subsection{Network Analysis}

We constructed a network of our panel countries for each of the ten years. Each of these networks had countries as nodes with edges connecting country pairs where there existed a

\footnotetext{
${ }^{3}$ Table formatted using Hlavac, 2014
} 
direct Internet connection using the $\mathbf{R}$ package igraph Csardi and Nepusz, 2006. Isolates (countries with no reported Internet connections with other countries) were not included in that year's network. Edges were weighted by the bandwidth capacity of that connection. This resulted in a 187 country network in 2002 and grew to a 201 country network in 2011. Figure 3 shows the basic structure of the 2011 global Internet network. There are 201 nodes (countries). The width of the edges is roughly proportional to the log of the bandwidth capacity represented by that edge. Some nodes have fairly high degree while others are only connected to one other country.

As suggested above, to visualize the relationship between regime type and Internet connectedness we need to look beyond country specific variables and consider how well connected or central that country is within the network. In this paper we consider several such measures. The first is simply to count the number of countries with which a given country has a direct Internet connection. In network terms, this is simply the degree of the country (node). In general we might expect that autocracies would be directly connected to fewer other countries than would democracies. This expectation is supported in Table 5. Given the heavy tailed nature of the degree distribution we report both means and medians with similar results for both statistics.

[Table 2 about here.]

A nodes degree simply reflects direct connections without considering the importance of the nodes being connected to. Our second measure, eigenvector centrality, tries to take into account the importance of the connections. The eigenvector centrality value of a node will be higher if that node is itself connected to high-eigenvector centrality nodes and lower if most of its connections are to low-eigenvector centrality nodes. Eigenvector centrality is a variant of the PageRank metric originally used by Google. The particular eigenvector centrality score we use is normalized (can take on values between 0 and 1) and weighted by the bandwidth associated with each connection. A country's eigenvector centrality score is not simply a function of what it does but is also a consequence of the direct connections and bandwidth volume of those connections held with those to whom it is connected. From our perspective, countries with higher normalized weighted eigenvector centrality scores are, in this sense, far more central within the network than are those with lower scores.

Figure 4 shows the same network as in Figure 3 though this time the nodes are colored to reflect their regime type and node size is proportional to its nomalized weighted eigenvector centrality score within that network. What stands out is that liberal democracies dominate the high (normalized weighted) eigenvector centrality scores. The top eleven are all democracies and all but Japan (polyarchy, rank 9) and Brazil (polyarchy, rank 11) are liberal democracies. The first autocracy is China (multiparty autocracy) at rank 12. The next non-democracy is Vietnam (closed autocracy) rank 55. The list is headed by the usual suspects, Great Britain, Germany, France, and the United States. Using eigenvector centrality as a measure of connectedness to the global Internet, regime type clearly matters.

[Figure 3 about here.]

As shown in Figure 5, the results in 2002 were similar with China (multiparty autocracy) as the highest ranking non-democracy with rank 15. Thirteen of the top fourteen were liberal 
democracies. Japan (polyarchy) had rank 10. The 2002 list was headed by the United States, Great Britain, France, and Canada.

[Figure 4 about here.]

[Figure 5 about here.]

The relationship between international bandwidth, Internet users, and regime type can be seen in the bubble plot in Figure 6. Here several things stand out. First, there is a rough linear relationship between a country's logged international bandwidth and their number of Internet users per 100 population. More importantly, however, the upper right portion of the plot tends to be occupied by liberal democracies (blue in color) with high eigenvector centrality scores (large diameter nodes). Moreover, most of these high eigenvector centrality nodes score relatively better on Internet users per 100 than they do on international bandwidth. A noteworthy exception is the United States whose bandwidth is considerably greater than what might be expected from its Internet users per 100 score. Both Russia and China (multiparty autocracies) rank lower on Internet users per 100 than their international bandwidth might suggest. On the other hand, several Middle East autocracies (United Arab Emirates, Bahrain, Quatar, Oman, and Kuwait) have Internet users per 100 scores higher than would be predicted from their international bandwidth levels.

[Figure 6 about here.]

Thus far we have not considered the role of economic development. This is addressed in Figure 7. While the roughly linear relationship between (logged) bandwidth and (logged) GNI is not surprising given prior literature, the importance of position in the global network as captured by normalized weighted eigenvector centrality again stands out. China and Japan are notable exceptions with GNI much higher than would be expected from their international bandwidth or normalized weighted eigenvector centrality score.

[Figure 7 about here.]

Finally, Figure 8 is similar to Figure 7 except that the y-axis is now Internet users per 100 population. In both Figures 8 and 7, blue (liberal democracy) nodes typically show greater Internet adoption (whether measured by users per 100 or international bandwidth) though the difference between democracies and autocracies is more distinct in the case of Internet users with normalized weighted eigenvector centrality as a strong discriminator at the high end of Internet adoption and GNI.

[Figure 8 about here.] 


\section{Conclusion}

This study examined the relationship between regime type and country access to the Internet at both domestic and global levels by conducting longitudinal analyses of economic, population, and Internet data from 2002 to 2011. In particular, we analyzed how a country's position in the global Internet network is related to the country's regime type while considering its economic growth and population. Our results show that it is important to look beyond country specific variables in this type of research and take into account how connected or central the country is within the overall global Internet.

At the country level our results are largely consistent with prior literature Milner, 2006. Regime type and economic development do matter for Internet adoption with richer and more democratic countries typically showing a higher degree of adoption (as measured by Internet users per 100) than do less democratic and poorer countries.

Our global level analysis extended the country analysis by constructing networks of international Internet connectedness and then examining how central countries were within this network as measured by both degree and eigenvector centrality. While generally in line with the country level analysis, network results highlight the importance of centrality especially as related to levels of economic development.

At both the country and network levels, scale (whether measured by population, degree, or normalized weighted eigenvector centrality) is an important discriminator. With notable exceptions (China and India), democracies with large populations and/or high normalized weighted eigenvector centrality scores show high levels of GNI. We speculate that citizens in countries with high centrality and easy access to the Internet have the capacity to generate ideas in greater numbers thus driving economic growth. This suggests that observed scale effects may well be more a function of citizens' level of informed access to the global bazaar of ideas than of simple population. Testing this speculation will be a next step in our research.

Future research should look more deeply into telecommunication policies and Internet regulations of countries over time as well as content filtering and censorship. This will help provide a more nuanced understanding of interplay between structural access to the global Internet and domestic Internet regulations policies and relationships of those factors with regime type. Given the number of countries in the global Internet and the number of years

for which we have fairly complete data, there is a limit to the number of parameters that can be included before running into over identification issues. That said, we have reported on mixture model of country level international bandwidth development in Seo and Thorson, 2015 and anticipate examining outliers in that model with respect to the economic and political variables discussed here. 


\section{References}

Aghion, P., Alesina, A. F., \& Trebbi, F. (2007). Democracy, technology, and growth. National Bureau of Economic Research Cambridge, Mass., USA.

Barnett, G. A. \& Park, H. W. (2005). The structure of international internet hyperlinks and bilateral bandwidth. Annals of Telecommunications, 60(9), 1110-1127.

Barro, R. J. (1996). Democracy and growth. Journal of economic growth, 1(1), 1-27.

Benkler, Y. (2006). The wealth of networks: how social production transforms markets and freedom. New Haven: Yale University Press.

Croissant, Y. \& Millo, G. (2008). Panel data econometrics in R: the plm package. Journal of Statistical Software, 27(2). Retrieved from http://www.jstatsoft.org/v27/i02/

Csardi, G. \& Nepusz, T. (2006). The igraph software package for complex network research. InterJournal, Complex Systems, 1695.

Freedom House. (2015a). Freedom in the world 2015. interactive map, online: https://freedomhouse. org/report/freedom-world/freedom-world-2015.

Freedom House. (2015b). Freedom of the press: 2015. Freedom House.

Global Internet Policy. (2015). Chaos 86 control: The competing tensions of Internet governance in Iran.

Guillén, M. F. \& Suárez, S. L. (2005). Explaining the global digital divide: economic, political and sociological drivers of cross-national internet use. Social Forces, 84(2), 681-708.

Hlavac, M. (2014). Stargazer: latex/html code and ascii text for well-formatted regression and summary statistics tables. R package version 5.1. Harvard University. Cambridge, USA. Retrieved from http://CRAN.R-project.org/package=stargazer

Howard, P. N. \& Hussain, M. M. (2011). The role of digital media. Journal of Democracy, 22(3), 35-48.

Jones, C. I. (1999). Growth: with or without scale effects? American economic review, 139144.

Kedzie, C. (1997). Communication and democracy: coincident revolutions and the emergent dictators.

Leydesdorff, L., Wagner, C., Park, H.-W., \& Adams, J. (2013). International collaboration in science: the global map and the network. El profesional de la información, 22(1), $87-95$.

Lipset, S. M. (1959). Some social requisites of democracy: economic development and political legitimacy. American political science review, 53(01), 69-105.

Magee, C. S. \& Doces, J. A. (2015). Reconsidering regime type and growth: lies, dictatorships, and statistics. International Studies Quarterly, 59(2), 223-237.

Milner, H. V. (2006). The digital divide the role of political institutions in technology diffusion. Comparative Political Studies, 39(2), 176-199.

Møller, J. \& Skaaning, S.-E. (2010). Beyond the radial delusion: conceptualizing and measuring democracy and non-democracy. International Political Science Review, 31(3), 261-283.

Møller, J. \& Skaaning, S.-E. (2013). The third wave: inside the numbers. Journal of Democracy, $24(4), 97-109$.

Munck, G. L. \& Verkuilen, J. (2002). Conceptualizing and measuring democracy evaluating alternative indices. Comparative political studies, 35(1), 5-34. 
Norris, P. (2001). Digital divide: civic engagement, information poverty, and the internet worldwide. Cambridge University Press.

Pemstein, D., Meserve, S. A., \& Melton, J. (2010). Democratic compromise: a latent variable analysis of ten measures of regime type. Political Analysis, 18(4), 426-449.

Rød, E. G. \& Weidmann, N. B. (2015). Empowering activists or autocrats? the internet in authoritarian regimes. Journal of Peace Research, 52(3), 338-351.

Romer, P. M. (1990, October). Endogenous Technological Change. Journal of Political Economy, 98(5), S71-102. Retrieved from http://ideas.repec.org/a/ucp/jpolec/v98y1990i5ps71102.html

Schumpeter, J. A. (2013). Capitalism, socialism and democracy. Routledge.

Seo, H. \& Thorson, S. (2015). A mixture model of global Internet capacity distributions. Journal of the Association for Information Science and Technology.

Seo, H. \& Thorson, S. J. (2012). Networks of networks: changing patterns in country bandwidth and centrality in global information infrastructure, 2002-2010. Journal of Communication, 62(2), 345-358.

Standage, T. (2013). Writing on the wall: social media-the first 2,000 years. Bloomsbury Publishing.

TeleGeography. (2012). Global Internet geography. PriMetrica, Inc.

Wagner, C. (2008). The new invisible college: science for development. Brookings Inst Pr. 


\section{List of Figures}

$1 \quad$ Regime Type by Year . . . . . . . . . . . . . . . . . . . . . . . . . . . . 15

$2 \quad$ Regime Type by Year . . . . . . . . . . . . . . . . . . . . . . 16

$3 \quad$ Global Internet $2011 \ldots \ldots \ldots$

$4 \quad$ Global Internet $2011 \ldots \ldots \ldots$

$5 \quad$ Global Internet $2002 \ldots \ldots \ldots$

$6 \quad$ Global Bandwidth, Internet Users, Regime Type, and Eigenvector Centrality;

$7 \quad$ Global Bandwidth, Eigenvector Centrality, Regime Type, and GNI; 2011 . . 21

8 Internet Users, Eigenvector Centrality, Regime Type, and GNI; 2011. . . . . 22 


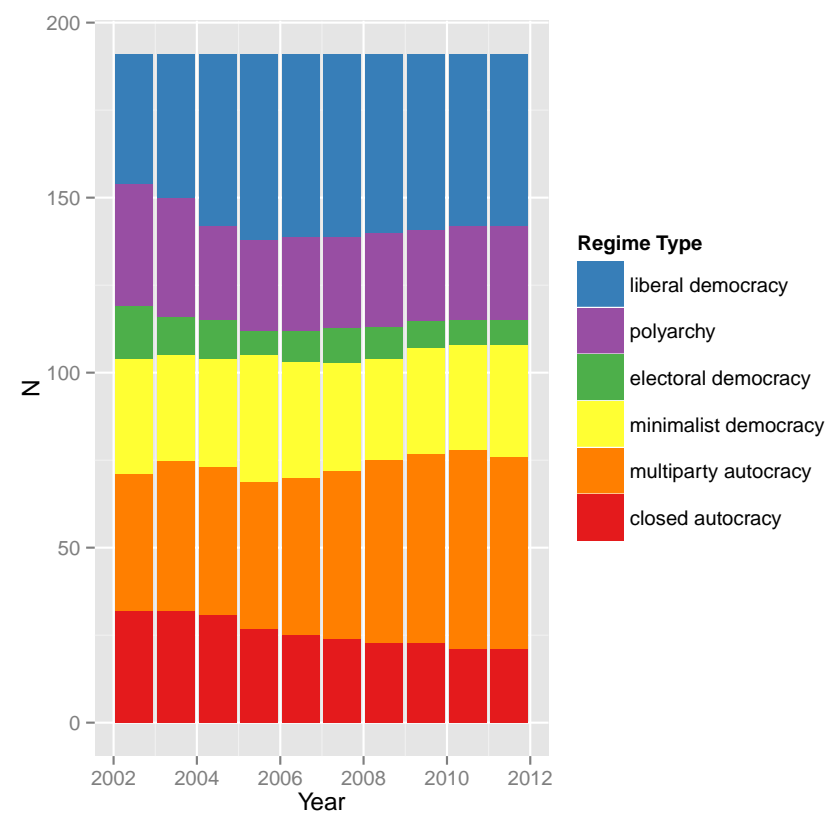

Figure 1: Regime Type by Year 


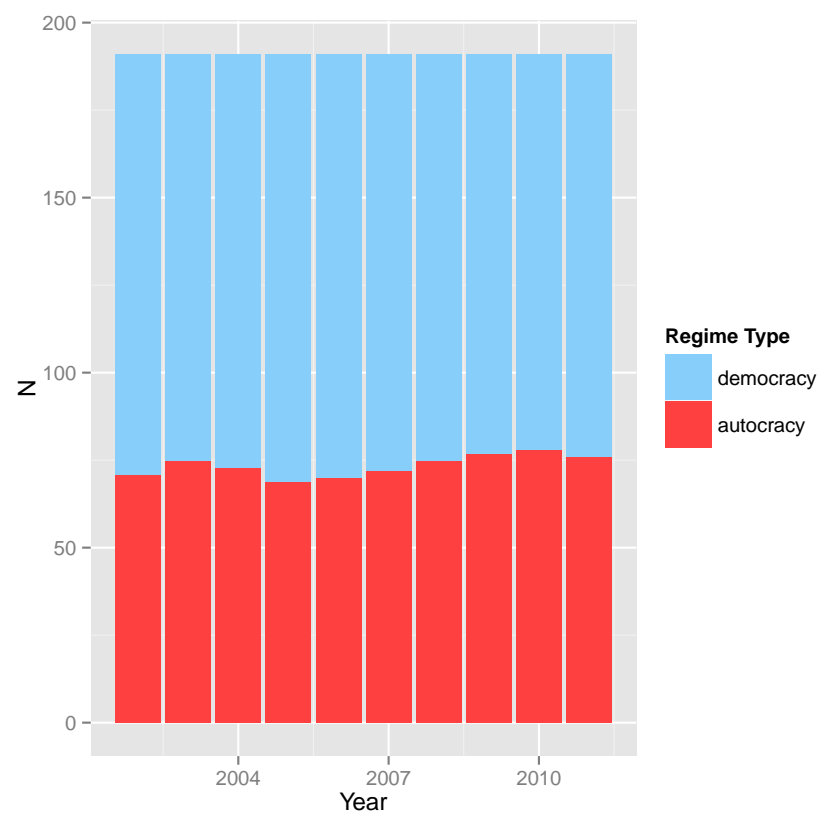

Figure 2: Regime Type by Year 


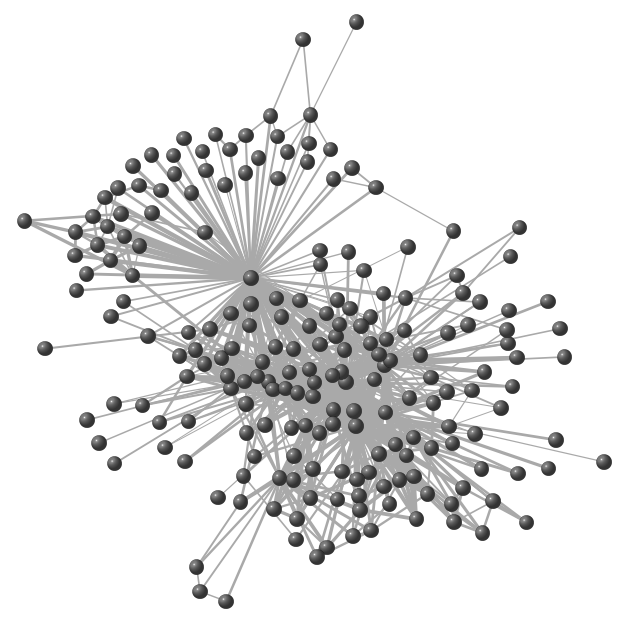

Figure 3: Global Internet 2011

Note: Edge widths proportional to log of edge bandwidth. 


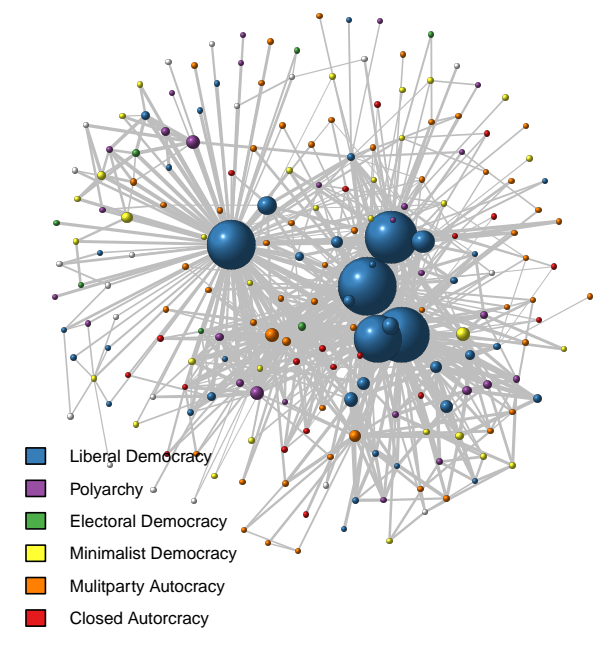

Figure 4: Global Internet 2011

Note: Vertex diameters proportional to their normalized weighted eigenvector centrality, edge widths proportional to log of edge bandwidth. Vertex color indicates regime type. 


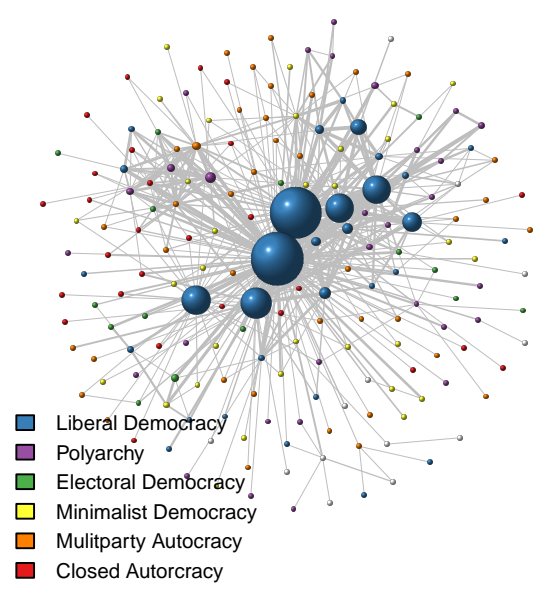

Figure 5: Global Internet 2002

Note: Vertex diameters proportional to their normalized weighted eigenvector centrality, edge widths proportional to log of edge bandwidth. Vertex color indicates regime type. 

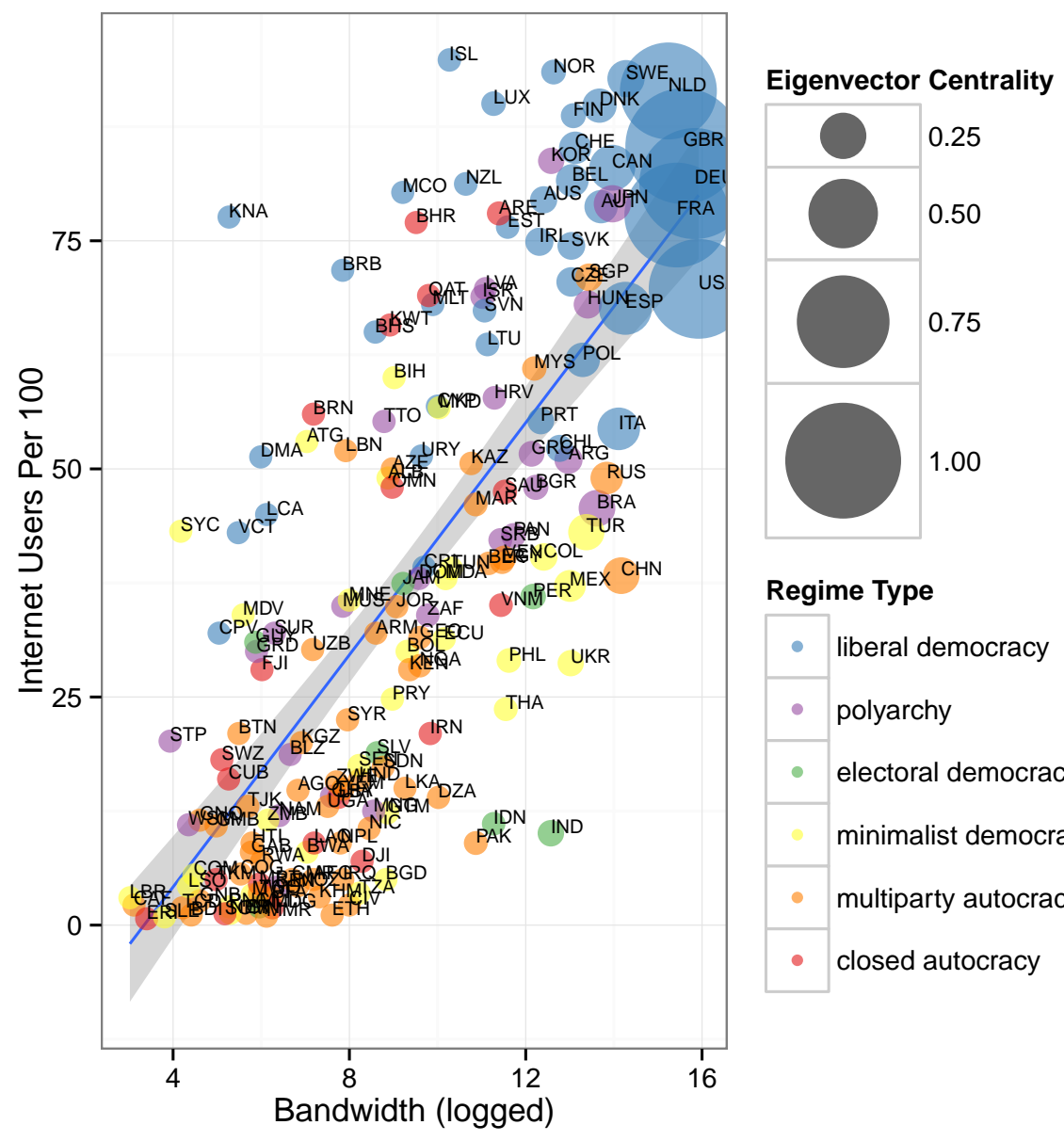

\section{Regime Type}

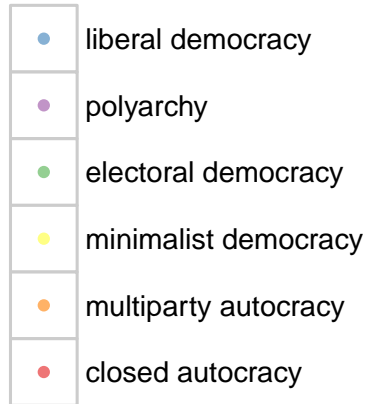

Figure 6: Global Bandwidth, Internet Users, Regime Type, and Eigenvector Centrality; 2011 Note: Points labeled with ISO3C country character code. 


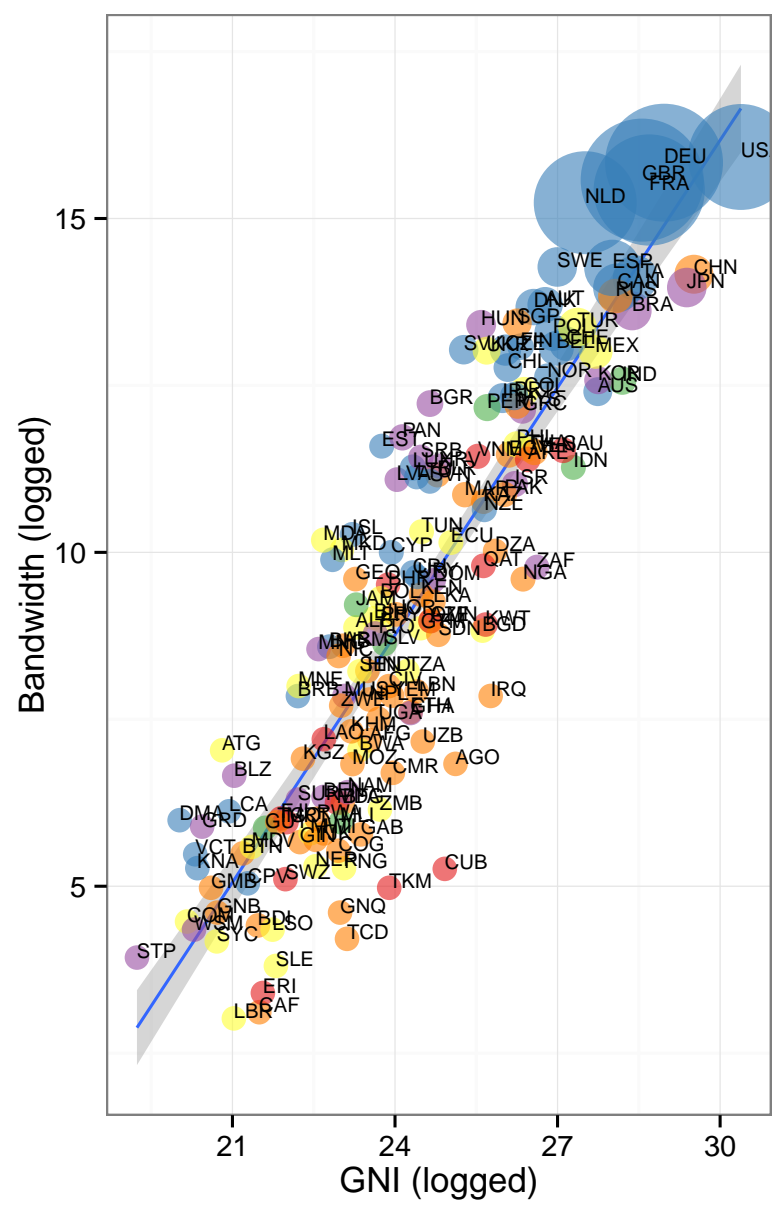

\section{Eigenvector Centrality}

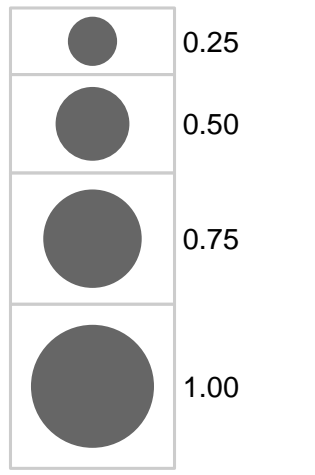

\section{Regime Type}

- liberal democracy

- polyarchy

- electoral democracy

minimalist democracy

- multiparty autocracy

- closed autocracy

Figure 7: Global Bandwidth, Eigenvector Centrality, Regime Type, and GNI; 2011 Note: Points labeled with ISO3C country character code. 


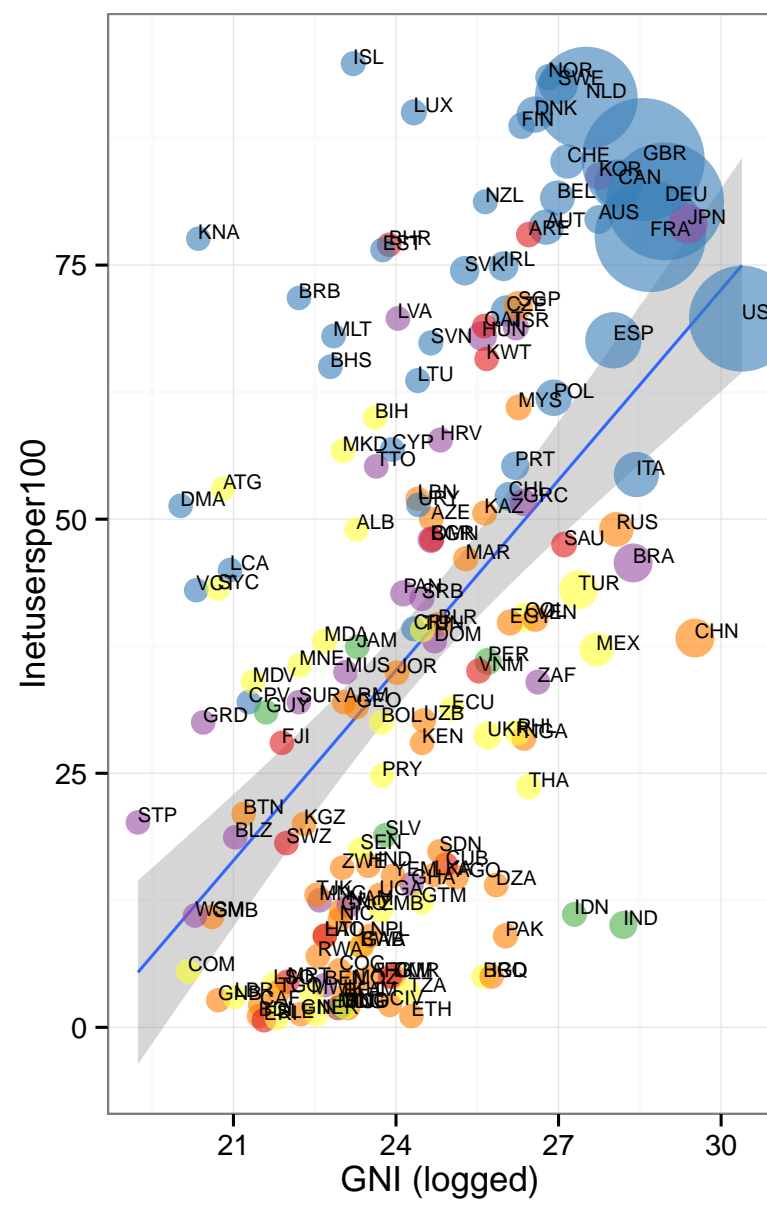

Eigenvector Centrality

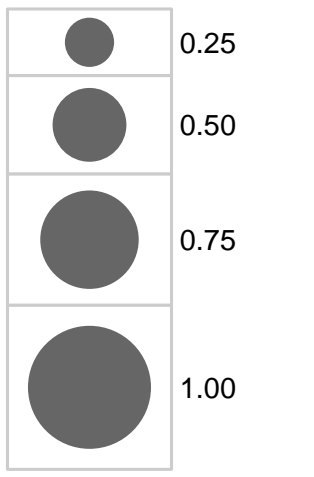

\section{Regime Type}

- liberal democracy

- polyarchy

- electoral democracy

minimalist democracy

- multiparty autocracy

- closed autocracy

Figure 8: Internet Users, Eigenvector Centrality, Regime Type, and GNI; 2011

Note: Points labeled with ISO3C country character code. 


\section{List of Tables}

$1 \quad$ Fixed Effects Panel Regression . . . . . . . . . . . . . . . . . . . . . . . . 24

$2 \quad$ Regime Type by Degree, $2011 \ldots \ldots \ldots \ldots \ldots$ 
Table 1: Fixed Effects Panel Regression

\begin{tabular}{lcc}
\hline & Inet Users per 100 & $\log (\mathrm{BW}) / \mathrm{POP}$ \\
& panel & panel \\
& $(1)$ & linear \\
& 62.50 & $(2)$ \\
\hline $\log (\mathrm{POP})$ & $\mathrm{t}=17.50^{* * *}$ & $\mathrm{t}=-6.0000$ \\
& 2.23 & 0.0000 \\
Regime Type & $\mathrm{t}=3.73^{* * * *}$ & $\mathrm{t}=1.79$ \\
& $-756,332.00$ & -1.81 \\
$\log (\mathrm{GNI}) / \mathrm{POP}$ & $\mathrm{t}=-5.68^{* * *}$ & $\mathrm{t}=-33.80^{* * *}$ \\
& 1,664 & 1,664 \\
$\mathrm{~N}$ & 0.26 & 0.45 \\
$\mathrm{R}^{2}$ & 0.23 & 0.40 \\
Adjusted $\mathrm{R}^{2}$ & $172.00^{* * *}$ & $406.00^{* * *}$ \\
$\mathrm{~F}$ Statistic $(\mathrm{df}=3 ; 1486)$ & &
\end{tabular}

${ }^{*} \mathrm{p}<.05 ;{ }^{* *} \mathrm{p}<.01 ;{ }^{* * *} \mathrm{p}<.001$ 
Table 2: Regime Type by Degree, 2011

\begin{tabular}{llrrr}
\hline & Regime Type & $\mathrm{n}$ & median degree & mean degree \\
\hline 1 & autocracy & 74 & 3.00 & 5.84 \\
2 & democracy & 107 & 6.00 & 9.85 \\
\hline
\end{tabular}

